Flamingos, edited by Janet Kear and Nicole Duplaix-Hall. Poyser, Berkhamsted, $£ 8.00$.

About 75 per cent of this conveniently sized and nicely produced volume is taken up by the 31 papers presented at the first International Flamingo Symposium, held at Slimbridge in July 1973. Of these, 15 deal with 'populations, ecology and conservation', six with 'flamingos in captivity', three with 'ethology and taxonomy' (the taxonomic item in this odd pair being Theresa Clay's interesting analysis of flamingo feather-lice), and the remaining seven with 'physiology'. Many are very technical, especially of course those of the last group, but are still well worth delving into for such intriguing bits of information as that the pigment canthaxanthin was first isolated not in a flamingo or other pink bird but in the orange-yellow chanterelle!

Most Oryx readers will no doubt find the first half of the papers most rewarding, containing as they do a thoroughly up-to-date and expert assessment of existing populations of the six different flamingos, and their conservation implications, which are in many cases still worrying. But increasing public awareness and concern, which many of the contributors to this book, not to mention institutions such as the New Grounds and the zoological gardens, have helped to promote, should eventually ensure that one of the most superb sights in the world will continue to be enjoyed.

An excellent introduction by Sir Peter Scott, not to mention the embellishment of his always highly evocative drawings, over 80 well selected photographs (six of them full-page colour plates), nine mainly statistical appendices and a comprehensive bibliography complete a book which can properly be described as a mine of information, needing some digging but full of riches. Leslie Brown's cautionary remark at the end of his paper is still apt: he calls for 'a readiness on the part of the researcher to jettison every conclusion he has come to after several years of painstaking work in the face of some new manifestation of contrariness on the part of these fascinating and beautiful birds'.

HUGH ELLIOTT

\title{
Threatened Birds of Europe, by Robert Hudson. Macmillan, £4.95.
}

Attractively produced, with nearly every species illustrated by a colour photograph, mostly full page, this book, despite the criticisms below, is well worth $£ 4.95$. About 700 words are devoted to each of 59 birds, in which an outline of the behaviour, appearance, and general characteristics is followed by a detailed analysis of status and a distribution map for the European range. However, information on distribution and status in other parts of the world is extremely scanty, and absent from the maps.

The major criticism concerns the choice of birds. The jacket 'blurb' describes the book as 'an appeal for help for 59 birds threatened with extinction in Europe', but the first species described, the great northern diver, is summarised as 'local, not immediately endangered'. The next two, Cory's shearwater and Leach's petrel, are summarised respectively as 'possibly threatened at some colonies' and 'not immediately endangered'. And the same applies to many others. Even more surprising is the inclusion of species such as spur-winged plover, terek sandpiper and white-rumped swift, birds which may be spreading in Europe. But the greatest omissions are the passerines; not a single species is mentioned. While it may be true that no passerine species is endangered and likely to become extinct, several surely have extremely small and vulnerable populations in Europe, while others, such as the rose-coloured starling, have undoubtedly disappeared from many parts of their range.

Unfortunately no references are given in the text, and the bibliography is brief, so it is difficult to check most of the data. For instance, where did the author learn 
that Basel Zoo has a captive population of 50 bald ibises? According to the International Zoo Yearbook they had 13. A statement on captive stocks, and their viability, for all other species being bred would have been useful.

My impression is that the publishers have imposed rigid restrictions of format which, while making the book attractive in appearance, have detracted from its ornithological value.

JOHN A. BURTON

Birds of the World: a check list, by James F. Clements. Two Continents Publishing Group, New York, \$15.

A Checklist of the Birds of the World, by Edward S. Gruson. Collins, $£ 3.95$. Birds: an illustrated survey of the bird families of the world, by John Gooders. Hamlyn, £6.95.

A complete check list of the birds of the world has been top of the list of ornithological desiderata for a very long time, in view of the fact that Peters's Birds of the World, started in the 1930s still lacks two volumes. Now, as so often happens, we have two plugs to fill the one gap. It is, of course, invaluable to have them; I only wish they had not both been so perversely pragmatic in their way of setting up the list. Just imagine setting out to create a list of birds of the world entirely from secondary sources, i.e. by consulting field guides and regional avifaunas. This is what both authors have done, Gruson more successfully than Clements. Inevitably there are shortcomings - Clements, for instance, has not picked up Pterodroma baraui, the new Réunion petrel. To my mind the only rational way of compiling a list of birds of the world is to start from Peters, and bring him up to date with the Zoological Record. Only with the tyrant flycatchers, the Old World warblers and the Old World flycatchers, occupants of Peters's missing volumes, should it be necessary to build up the list de novo from the literature.

Still, we should be thankful for what we have, however out-of-date some of their nomenclature - Gruson has not caught up with Phoebetria for two of the albatrosses, and neither author has achieved Calonectris in the shearwaters or Tachybaptus in the grebes. What is more, Clements caters for the classificatory heretics who like to put the crows near the beginning of the passerines, while Gruson sticks to Petersian orthodoxy and puts them at the end. It is a slight pity that we have two lists with so many differences in the order in which the families are listed.

These two books are for the specialist (who may nark a bit) and for the tick hunter. John Gooders has written a book of quite a different genre, one that will give the greatest pleasure to ordinary bird watchers, and comparable with Austin and Singer's and Gilliard's books on the birds of the world. Though it has been done before, its predecessors are mostly out of print, and it is useful to have it done again in this large volume of 350 pages, with good summaries of the characteristics of each bird family and over 400 excellent colour photographs.

RICHARD FITTER

\section{The Identification of Mammalian Hair, by Hans Brunner and Brian Coman.} Inkata Press, Melbourne £13.25.

This well produced book demonstrates a method of compiling a photographic index to hairs of a limited group of mammals. Unfortunately the title omits the essential information that it is designed primarily for ecologists working on the fauna of Victoria State, Australia.

The first eighteen pages include basic information on hair types, growth and the nomenclature for hair characters, the latter closely following Wildman (1954) with a few modifications. Descriptions of simple techniques and a system for the study of hairs are useful additions to this section and are of general interest. So 